\title{
Measuring Creative Performance of Teams Through Dynamic Semantic Social Network Analysis
}

\author{
Xue Zhang ${ }^{1}$, Peter A. Gloor ${ }^{2}$ and Francesca Grippa ${ }^{3}$ \\ ${ }^{1}$ Department of Mathematics and Systems Science, National University of Defense Technology, \\ Changsha, Hunan, P.R.China \\ xuezhang@nudt.edu.cn \\ ${ }^{2}$ MIT Center for Collective Intelligence, Cambridge, MA, U.S.A. \\ pgloor@mit.edu \\ ${ }^{3}$ Northeastern University, Boston, MA, U.S.A. \\ f.grippa@neu.edu
}

\begin{abstract}
In this project we compare communication structure and content exchanged by members of creative, interdisciplinary teams of medical researchers, physicians, patients and caretakers with their creative output. We find that longitudinal social networking patterns and word usage predict creative performance. We collected the e-mail archives of 60 members of a community of researchers working on 12 projects improving various aspects of the daily lives of patients of Crohn's disease. Our results indicate that more creative projects show a decrease in group density, while more actors are involved, and more emails are exchanged, suggesting that a more successful project attracts more attention from many different people. We also found that members of more creative projects use more outspoken language, which gets more focused over time.
\end{abstract}

\section{Introduction}

Early studies on organizational creativity were focused mainly on the role of individual actors and explored personality traits of highly creative people (Simonton, 1984; Barron and Harrington, 1981; Helson, 1996). Early work by Singh (1986) found that personality data was correlated with biographical data, potentially predicting the emergence of creative behaviors from individual qualities.

This paper goes beyond the traditional psychological approach that seeks to explain creativity based on personal traits and qualities of individuals. We explore the context in which creativity emerges and the structural properties of creative teams. Given the importance of teamwork and other forms of job sharing in today's work environment, we study the structural properties of creative teams to learn more about the mechanisms used by knowledge workers to share innovative ideas and improve organizational performance. In terms of organizational creativity, little is known about the effect of various work relationships (Perry-Smith, 2006). In this paper 
we investigate the role of different patterns of relationships, and the influence of social ties in the work context.

Creative people differ both in with whom they communicate, and what they say (Csikszentmihalyi, 1997). This paper extends earlier work, where the authors found that oscillating communication structure in the e-mail networks of Eclipse open source developers predicted their creativity and productivity (Kidane \& Gloor, 2007). The goal of this research is to compare the communication structure and content within a team with its creative output. In particular, we are analyzing the work processes of the $\mathrm{C} 3 \mathrm{~N}$ project, a multiyear research effort spearheaded by Cincinnati's Children Hospital, fostering collaboration between patients, doctors, and researchers of Crohn's disease and ulcerative colitis. The communication structure is calculated automatically by constructing the social network of project participants through one year's worth of e-mail of the $\mathrm{C} 3 \mathrm{~N}$ project team. The creative output is measured through 12 subprojects - called "prototypes" in the C3N project - addressing various aspects of Crohn's patients, with the goal of improving the daily lives of patients.

\section{Team Creativity}

\subsection{Organizational Creativity and Creative Performance}

Organizational creativity is an important component of organizational change, being the seed of all innovations (Amabile et al., 1996). It has been the subject of extensive literature in the areas of innovation management and organizational behavior (Steiner, 1969; Amabile, 1983, 1996; Woodman et al. 1993). Organizational creativity has been conceptualized as "the creation of a valuable, useful new product, service, idea, procedure, or process by individuals working together in a complex social system" (Woodman et al, 1993, p. 293). Creativity in the organizational context is often identified as the output of a collective effort within the context of an organization and involves the adaptation of existing ideas to develop new knowledge (Amabile et al., 1996). The interactional perspective on creativity suggests that the effective translation of ideas into action will depend on a variety of individual and situational attributes such as motivation, skills, personality, and contextual features (Zhou et al., 2009; Woodman et al., 1993).

Amabile (1983) proposes a theory of organizational creativity known as the 'componential model of creativity' to explain the interactions of social and environmental factors with personality characteristics and the effects of these factors on creativity. Amabile identifies three factors that influence organizational creativity: i) intrinsic task motivation, ii) domain-relevant skills, and iii) creativity-related processes, which translate into management practices conducive to innovation. Individuals are most likely to be more creative when these three components overlap. The interactional perspective on creativity suggests that the effective translation of ideas into action will depend on the 'creativity intersection' among both individual and organizational factors. Amabile's model suggests how individual skills and motivation affect the progress of the innovation process (Zhou et al. 2009; Woodman et al., 1993).

Social cognition researchers describe a phenomenon called 'observational learning' or 'modeling' based on evidence that observing colleagues displaying creativity at work may lead to participation in creative activities as well (Bandura, 1986). This organizational and contextual factor suggests that employees' creativity could be influenced by the presence of creative collaborators. Based on the studies mentioned above, we define 'creative performance' as the 
ability to transform novel ideas into successful products and processes. In our view, creativity represents a starting point for organizational innovation.

The literature on organizational creativity has often used interchangeably the concepts of 'team performance' and 'team creativity' with the assumption that a high-performing group or individual must be more creative (Hackman and Katz, 2010). Instead of assessing group performance sensu lato, we specifically investigate the emergence of creative behaviors in teams involved in innovative processes. Instead of considering performance and creativity as two different concepts, we adopt the concept of 'creative performance' to focus on the structural and relational properties of creative teams that could improve innovation and increase performance (Shalley and Perry-Smith, 2001; Perry-Smith, 2006). As pointed out by many researchers, it is not enough to be inventive and creative to produce a breakthrough idea able to meet the market needs. Instead, it is important to distinguish creative and feasible ideas from bizarre ideas that may be unrealistic and not feasible for the organization to implement (Amabile, 1996).

\subsection{Creativity in Teams}

Recent studies on organizational creativity are more focused on investigating the social origin of new ideas going beyond individual cognitive processes (Grant and Berry, 2011; Sawyer, 2009, Pirola-Merlo and Mann, 2004). Based on the assumption that highly creative processes happen in a state of flow (Csikszentmihalyi, 1997), it has been demonstrated that it takes often other people for a person to reach the state of flow (Collins, 2005). While other individuals do not have to be physically present, they are however present in the mind of the person reaching the flow state. In a field experiment involving a jazz band made of eight musicians, Gloor et al. (2013) extended the concept of individual "flow" as defined by Csikszentmihalyi (1997) to the group level. The authors used sociometric badges with the goal of identifying some of the prerequisites for "flow", the state of work where the individual is at his/her most-productive state.

Uzzi and Spiro (2005) studied the small world networks of creative artists involved in Broadway musicals from 1945 to 1989. The Broadway musical network shows that links between teams emerge when artists work in more than one musical and create dense overlapping clusters of the type that are prototypical of a small world network. This and similar studies are demonstrating the need to find new ways to investigate group dynamics among selforganizing teams, based on the assumption that relying exclusively on laboratory settings might lead to results that are difficult to extend to real world situations.

Here we adopt a longitudinal approach to study the evolution of project teams. We rely on the concept of Collaborative Innovation Networks (COINs) to observe the team's creative behaviors over time. COINs are made up of groups of self-motivated individuals linked by the idea of something new and exciting and by the common goal of improving existing practices, new products or services for which they see a real need. The strength of COINs is based on their ability to activate creative collaboration by leveraging social networking mechanisms, affecting positively individual capabilities and organizations' performance (Gloor, 2006).

\subsection{Measurement of Creativity}

Contextual theories of organizational creativity have been focused on studying the impact of environmental events to explain creative behaviors. Most of this work is primarily based on individual perceptions based on the psychological meaning that respondents attach to events in their organizations or in their team (Shepers and van den Berg 2007, Amabile et al., 1996). For example, Amabile and colleagues (1996) propose a conceptual model and an assessment instrument, KEYS, assuming creativity as a 'continuous quality' that can be assessed on a scale 
from very low to very high. Amabile et al. (1996) rely on primary sources, including a review of previous studies and surveys to R\&D researchers and technicians.

Several authors have tried to predict the emergence of creative behavior by conducting experiments in a laboratory setting. According to Eysenck (1993), creativity as an individual quality can be assessed using word association tests, where high scores on these tests are correlated with scores of individuals who have done highly creative work. Eysenck proposed a distinction between 'creativity as a trait' and 'creativity as unique achievement', suggesting that creativity is a rare achievement and that actual creative behaviors are dichotomous, as individuals either produce creative work or not.

Another framework to analyze creative output of small groups measures fluency and flexibility, fluency referring to the number of non-redundant ideas, and flexibility referring to the number of idea categories represented in ideas (Choi and Thompson, 2005). Goncalo and Staw (2006) recently studied group creativity and the effect of individualistic and collectivistic values. In a laboratory setting people were asked to generate ideas in a 15 minute period, while two additional coders rated each idea for creativity based on criteria of originality and novelty. This subjective rating of creativity can be considered a limitation of this type of study. Simply counting the number of different ideas and idea categories does not really account for the impact and quality of the creative ideas.

Cummings and Kiesler (2008) studied the success of over 500 interdisciplinary research projects sponsored by NSF. They found that while distance of interdisciplinarity reduces creative output, prior collaboration mitigates this effect. They measured creative output of the teams in four dimensions: knowledge (e.g. publications), tools (e.g. software), training (e.g. Ph.D students), and outreach (e.g. museum installations). Their results illustrate that just ranking the number of creative tasks is a poor predictor for long-term creativity.

The main limitation of these studies is the possible bias introduced by respondents' perceptions. To overcome this limitation, our study extends traditional sources such as questionnaires and interviews with sources that provide a potentially more objective picture of creative behavior. Through mining email archives and automatically searching for positive and negative attributes within a team's communication, we aim to reduce the issues of a bias introduced through selfreport responses to questionnaires.

A recent stream of research is now adopting innovative technologies such as sociometric badges to assess group performance. For example, Olguin-Olguin, Gloor and Pentland (2009) used the data collected with these sensors and estimated the daily average length of stay (LOS) as well as number of delays in a Postanesthesia Care Unit (PACU) of a Boston area hospital. Gloor et al. (2012) used sociometric badges to investigate the factors enabling collective creativity, looking at individual and collective patterns of social behavior. The authors found that the more team members directly interact with each other face-to-face, and the more they trust other team members, the more creative and of higher quality the result of their teamwork is.

These and similar studies have been focusing so far on assessing group performance, rather than specifically address the emergence of creative behaviors conducive to innovation. In this paper we propose an innovative method to assess the emergence of creativity by correlating social network metrics and content-based semantic analysis metrics with creative performance. 


\subsection{Using Social Network Analysis to Measure Creativity in Teams}

In this research we consider creativity as an important social process; therefore we study how the structure of the social context can help understand the emergence of creative behaviors.

Researchers have long discussed the structural properties of networks trying to identify the most effective configuration to build social capital defined as a specific property of social organizations, such as trust, norms and networks enabling coordinated action to potentially improve the efficiency of organizations, teams and society in general (Coleman, 1988). This research is also informed by two important concepts introduced by Putnam to explore the depth of social interactions within and across groups (Putnam, 2000): 'bridging social capital' referring to bonds of connectedness that are formed across diverse social groups - and 'bonding social capital' referring to strengthening ties in homogenous groups. Bridging and bonding should not be considered "'either-or' categories into which social networks can be neatly divided, but 'more-or less' dimensions along which we can compare different forms of social capital" (Putnam 2000: 22-24). According to Putnam, bridging and bonding social capital have different consequences and effects on organizations and social groups: while bonding social capital seems to be positively associated to enable reciprocity and solidarity, bridging social capital seems to be oriented to push forward growth and development.

There is still no definitive agreement on whether network configurations such as high density or the presence of structural holes have a positive or negative impact on innovative performance (Cummings and Cross, 2003; Ahuja, 2000). For example, Perry-Smith (2006) studied the effects of relationship strength, network position, and external ties on individual creative contributions. The results of this research suggest that "weak ties facilitate creativity and that strong ties do not" (Perry-Smith, 2006: 96). The author also found that centrality was positively correlated with creativity when individuals had few connections outside of the organization, while the combination of centrality and numerous outside ties was not optimal.

In this ongoing debate within the innovation literature as to which network configuration and type of social capital is more conducive to innovation, there seems to emerge two different views, one based on network closure and the other focused on structural holes. Following the work of Coleman (1988), the 'cohesion theory' emphasizes the importance of creating dense networks since intense connections help create a social structure that favors communication, coordination and trust among the involved individuals (Coleman, 1988; Moran, 2005). This view emphasizes the importance of network properties like closure and assumes that dense networks increase the probability of developing strong ties, building trust, strengthening group identify and facilitating the transfer of tacit knowledge, which are all elements likely to favor an organization's innovative performance.

Conversely, another stream of research emphasizes the role of abundant structural holes (Burt, 1992), since sparse networks are more likely to encourage diversity of knowledge and loose networks characterized by many weak ties can help in the acquisition and dissemination of novel ideas (Granovetter, 1973).

More recent studies aimed to demonstrate the validity of both approaches suggesting that Burt's social capital theory might complement Coleman's theory. Rost (2011) found an inverted Ushape relationship between strength of ties and innovation. The results indicate that a dense network helps create trust, which has a positive influence on innovation, but only up to a certain point, after which its effect diminishes and turns negative. It seems that over time ties that are excessively strong lead to a negative effect in terms of innovative performance. 


\section{Theoretical Model}

Our theoretical model combines two methods to analyze social capital, namely Social Network Analysis (SNA) and content analysis. SNA helps identify structural properties of social networks, providing measures such as density, centrality and structural holes. Content analysis offers a deeper level of understanding about the quality of the relationships, looking at the content exchanged in the relationship, providing insights into the attitude of the actors involved in the exchange with respect to a list of topics found in a document.

Social Network Analysis is an interdisciplinary method to analyze social structures that explores the relational aspects of these structures (Wasserman and Faust, 1994). As Goodwin and Emirbayer (1994) pointed out, social network analysis is a framework devoted to the investigation of the information structure of organizations, with a specific focus on the "structural dimension" of social capital, and less emphasis on the content of the relationships (the content of ties). SNA has an intrinsic limitation as it considers all the ties in a network as comparable, indistinguishable and homogeneous in content: actors performing different activities or involved in different projects are considered as "members in interaction" with little understanding of the context of their interaction. Stinchcombe (1990) expressed the need to articulate a systematic theory of social networks coming from the dynamic and causal dimensions of the relationships, able to investigate ties among social actors using both a quantitative and qualitative approach through the investigation of the content exchanged. Semantic analysis and other text analytics techniques are complementary research methods for making inferences from texts about the context of their use. In this research we classify the content exchanged via emails based on the overall opinion about a topic. In this regard, content analysis helps us determine whether a message exchanged by team members is positive or negative, open or focused.

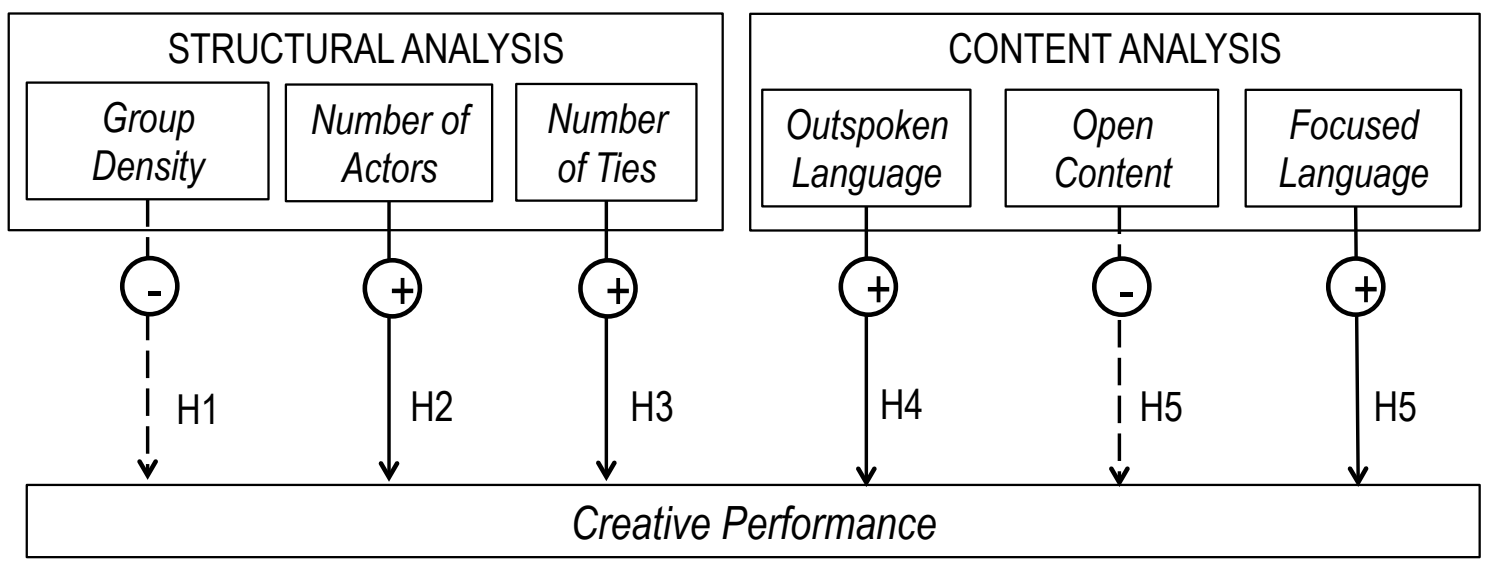

Figure 1. Theoretical Model

To test our model, we designed an empirical study that investigates the networking behavior of a creative team, measuring both the structural properties and the content exchanged in the communication. Figure 1 illustrates the theoretical model combining network structural properties with content analysis. 


\section{Hypotheses}

Following Burt's approach (1992), we aim to demonstrate that strong ties may lead over time to the convergence of knowledge within a team, with the subsequent reduction of diversity of opinions negatively affecting the emergence of creativity. In our research we assume that dense networks might lead to redundant ties between members, limiting the flow of different ideas and possibly hindering access to new information.

Overall, we expect that the more team members have access to a large network, the more people are engaged in communicating about a new project idea. Network density-calculated as the total number of ties divided by the total possible number of ties - impacts teams' performance by fostering creativity from less closely connected groups. As demonstrated by a recent study by Bulkley and Van Alstyne (2006) strong email ties to teammates are associated with network advantages, corroborating the search transfer paradigm (Hansen, 1999). Hansen (1999) found that when information is complex, transferring it from one context to another becomes difficult without strong ties to support mutual understanding. This leads to our first three hypotheses.

\section{H1: The less dense the network is, the more successful is the team.}

H2: The larger the number of people involved into the discussion, the more successful is the team.

\section{H3: The higher the e-mail traffic is, the more successful is the team}

Predicting real world events based on the communication structure and contents of online networks is a rapidly emerging field (Pang and Lee, 2008). Krauss et al. (2008) proposed a model based on sentiment analysis to predict Academy Award nominees based on the communication of an online community. By applying the same approach to studying the correlation between communication within the community and movie success at the box office, they found that a positive discussion by trendsetters predicts success of a newly released movie at the box office. While sentiment analysis is increasingly used to study how positive and negative opinions propagate and how they influence people in the context of online communities, there is still a lack of empirical evidence about the way ideas spread within organizations. Based on the results of studies mentioned above, we assume a similar positive correlation between positivity of the language used and ability of a creative team to reach its goal.

We expect that the more emotional in positive and negative terms they talk about a project idea, the higher is their creative performance. This means that they give more outspoken feedback to each other, which has been shown in earlier research to increase creative performance (Gloor et al., 2012). Therefore, we hypothesize that:

H4: The more outspoken the language is, i.e. the more both positive and negative terms are used, the more successful is the team.

Finally, the more a project progresses, the more its team members will focus on their own subproject, while abstaining from discussing the other prototypes. Our model therefore assumes that the longer a project has been progressing, the more focused the language becomes and the less team members will be talking about other prototypes.

H5: The longer the project is moving on, the more focused the language becomes and the less open it is. 
In our research a 'focused' communication is defined as the extent actors are talking exclusively about the terms identifying their own project ideas, without mentioning the other projectsrelated concepts. An 'open' communication is defined by the extent actors mention concepts from other projects that are external to their own project's idea. This means they will be using words listed in table 1 describing other projects.

\section{Method}

\subsection{Data Collection Process}

We collected the email archives of ten key members of the C3N project twice, in August 2011 and in January 2012. We subsequently removed the duplicate messages and merged the data into one database. The emails have been exchanged mostly between January 2011 and January 2012. However, because of issues due to institutional email management policies, we were able to use only nine months of emails (from March 2011 to January 2012). The analysis was done with the Condor social network analysis tool (Gloor et al., 2003). Condor creates visual maps, movies and network metrics of relationships related to social networks by mining email archives, web site link structures, and online forums.

In this research we combine social network analysis with sentiment and content analysis (Gloor \& Zhao, 2006). Besides collecting data about sender, receiver and the time an email was exchanged, we also included the sentiment of the e-mails' contents. Sentiment analysis has been an active topic of research for at least the last 20 years. Initially NLP (natural language processing) approaches have been employed, by classifying the semantic orientation of words or phrases (Hatzivassiloglou \& McKeown, 1997). More recently machine-learning based methods have been shown to be successful (Bo et al., 2002). Another approach consists of using the manual or semi-manual construction of discriminant word lexicons (Das \& Chen, 2001), although it has been shown that humans do not always have the best intuition for choosing discriminating mood words (Bo et al., 2002). In other work Bollen et al (2011) found that by not focusing simply on positivity and negativity, but calculating a dictionary for the six Point of Mood States (Calm, Alert, Sure, Vital, Kind, and Happy) led to better predictions of Twitter for the stock market. In our experiment we calculate positive and negative sentiment in the e-mail text using a simple "bag-of-words" approach (Whitelaw, 2005), employing user-generated mood word lists relevant for the domain area to calculate positivity and negativity of an e-mail's content. For each email, sentiment words matching the lists were counted and then normalized by the total number of words in each message. Thus each email has both a positivity value and a negativity value ranging from 0 to 1 .

Our method therefore employs the approach expressed by Stinchcombe (1990), who articulated a systematic theory of social networks expressing the dynamic and causal dimensions of the relationships, able to investigate ties among community members not only under the quantitative aspect related to the SNA metrics, but also under the qualitative aspect related to the content of the ties. This approach will help give meaning to both the "relational" and "cognitive" dimensions of social capital.

\subsection{The Prototypes Teams}

Our units of analysis for the output of the creative teams are 12 different subprojects called "prototypes". These are different project ideas developed individually and in group brainstorming sessions by the $\mathrm{C} 3 \mathrm{~N}$ team in 2010 . Similarly to many other teams in the R\&D 
environment, these creative teams act as self-managing groups with tasks going from executing the work to measure, assess and manage their own activities (Hackman and Katz, 2010). There are 12 different prototypes in the $\mathrm{C} 3 \mathrm{~N}$ project, which are listed below in table 1.

\begin{tabular}{|c|c|c|}
\hline Name & Search Terms & Description \\
\hline Mentoring & mentoring & $\begin{array}{l}\text { Creating }+ \text { supporting 1:1 relationships and activities for children } \\
\text { and adults living with Inflammatory Bowel Disease }\end{array}$ \\
\hline Youapp & youapp & $\begin{array}{l}\text { YouApp connects IBD patients with similar interests through their } \\
\text { Facebook Networks, by proposing them "people like themselves" } \\
\text { based on their self-defined attributes and a game-like quiz with } \\
\text { user-definable questions }\end{array}$ \\
\hline $\mathrm{N}$ of 1 & $\mathrm{n}$ of 1 & $\begin{array}{l}\text { "N-of-1 trials" are experiments designed to determine how } \\
\text { individual patients respond to specific treatments or interventions. }\end{array}$ \\
\hline Patient Activation & $\begin{array}{l}\text { patient activation, } \\
\text { aim } 2 \mathrm{~b}\end{array}$ & $\begin{array}{l}\text { An activated patient is someone who understands that they must } \\
\text { take charge of their health and that actions influence outcomes. }\end{array}$ \\
\hline Passive PRO & $\begin{array}{l}\text { passive pro, } \\
\text { ginger.io }\end{array}$ & $\begin{array}{l}\text { This intervention is investigating the use of mobile sensing } \\
\text { technology to assess the feasibility, acceptability, and validity of a } \\
\text { passive PRO for use in an adolescent IBD population. }\end{array}$ \\
\hline Social Games & $\begin{array}{l}\text { social games, } \\
\text { virtual camp oasis, } \\
\text { innocentive challenge }\end{array}$ & $\begin{array}{l}\text { Mobile social games using game dynamics and the peer network to } \\
\text { engage adolescents in a) creating community b) improving the } \\
\text { health of the whole community of those suffering from IBD, and } \\
\text { c) enhancing self-management }\end{array}$ \\
\hline $\begin{array}{l}\text { Building } \\
\text { Community } \\
\text { Leadership }\end{array}$ & $\begin{array}{l}\text { community leadership, } \\
\text { marshall ganz, } \\
\text { bcl }\end{array}$ & $\begin{array}{l}\text { Build an activated, empowered and distributed community of } \\
\text { patients, parents, clinicians and researchers who will recruit new } \\
\text { leaders and carry out the work of the } \mathrm{ICN}^{1} / \mathrm{C} 3 \mathrm{~N} \text {. This will occur } \\
\text { through participation in distributed leadership teams, parent group, } \\
\text { patient advisory council, etc. }\end{array}$ \\
\hline $\begin{array}{l}\text { Population } \\
\text { management }\end{array}$ & population management & $\begin{array}{l}\text { Use Quality Improvement methods to implement enhanced IBD- } \\
\text { registry features to enable management of IBD care center patient } \\
\text { populations and to increase patient participation in care. }\end{array}$ \\
\hline Pre-visit Planning & pre-visit planning & $\begin{array}{l}\text { Use Quality Improvement methods to implement enhanced IBD- } \\
\text { registry features to enable timely pre-visit planning for IBD } \\
\text { populations. }\end{array}$ \\
\hline $\begin{array}{l}\text { Patient Advisory } \\
\text { Council }\end{array}$ & patient advisory council & $\begin{array}{l}\text { A council of exceptional pediatric patients with IBD to serve and } \\
\text { advise both the C } 3 \mathrm{~N} \text { and ImproveCareNow's community building } \\
\text { efforts and other initiatives }\end{array}$ \\
\hline $\begin{array}{l}\text { Peer Produced } \\
\text { Practice } \\
\text { Knowledge }\end{array}$ & $\begin{array}{l}\text { peer produced practice } \\
\text { knowledge, } \\
\text { p3k, } \\
\text { peer production }\end{array}$ & $\begin{array}{l}\text { Intervention to provide Improve Care Now with the technology } \\
\text { and support to document what they are learning about how to } \\
\text { make changes and innovations in care delivery and to explore, } \\
\text { assess the value, and refine the information contributed by others. } \\
\text { Active development of a large on-line community and easily } \\
\text { accessible resources. }\end{array}$ \\
\hline $\begin{array}{l}\text { Social Network } \\
\text { Analysis }\end{array}$ & social network analysis & $\begin{array}{l}\text { The Social Network Study is designed to anonymously describe } \\
\text { and analyze the social network connections and communications } \\
\text { between IBD care team members at C3N practice sites, with a } \\
\text { view toward using that information to help improve team } \\
\text { performance and ultimately, patient-level clinical outcomes. }\end{array}$ \\
\hline
\end{tabular}

Table 1. Prototypes and Condor search words to filter e-mail networks

\subsection{Data Analysis}

To construct the social network through the e-mail network, we filter for descriptive and distinctive search words for each prototype. They are listed in column two in table 1. For example, in order to get the emails of the group "patient activation", we select the emails that contain either "patient activation" or "aim $2 b$ ".

\footnotetext{
${ }^{1} \mathrm{ICN}$ (Improvecarenow) is the predecessor organization of $\mathrm{C} 3 \mathrm{~N}$, a network of primary care physicians of IBD patients.
} 

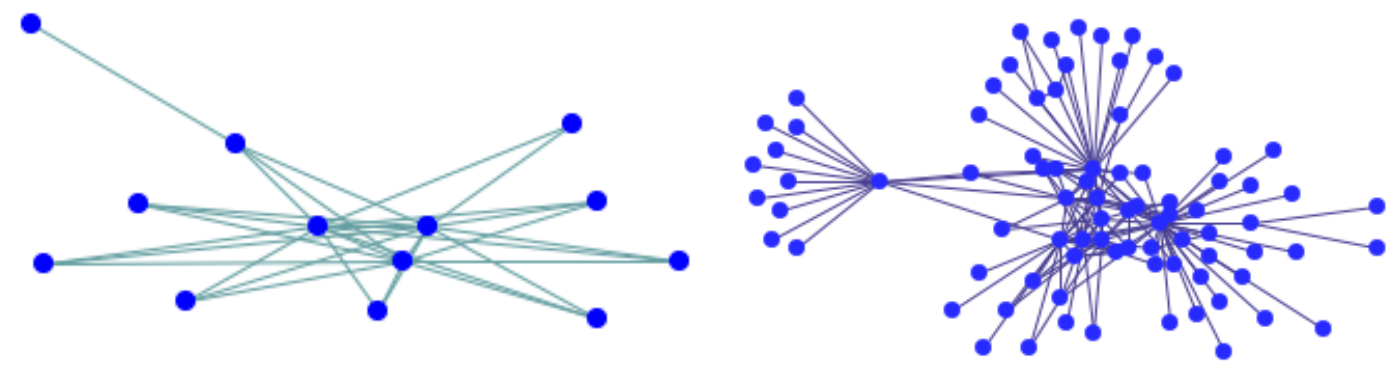

Figure 2. Two e-mail networks (left: peer production, right: $n$ of 1)

Out of the e-mails filtered for each prototype we construct a social network for each month. Figure 2 shows two typical networks, a relatively sparse one for the "peer production" prototype, and a much denser one for the " $n$ of 1 " prototype. The core team members for each prototype team range from 3 to 12 , again following the basic rules of COINs. There is no firmly established number of initial members of a prototype team. Rather, this follows the COINs approach, where a creator with a novel idea conducts a "waggle dance" to recruit additional members to the project (Gloor, 2006). The concept of waggle dance derives from the collective behavior of bees: the swarm sends out the coolhunters, the most committed and experienced bees, to scout for a new location of the hive. These bees act in rotating leadership, vote on each other's proposed new hive settings and agree on a new location. Based on the intensity of their waggle dance, the experienced bees convince each other and their sisters. This seems to correspond to the human behavior typical of a COIN, where highly committed individuals develop a new product, and then recruit other members to fine-tune the product (Gloor and Cooper, 2007).

\begin{tabular}{|l|l|l|}
\hline Status of Project & Operational Definition of Status & Score \\
\hline $\begin{array}{l}\text { Prototype and } \\
\text { team initiation }\end{array}$ & $\begin{array}{l}\text { Prototype has been identified, team members have been } \\
\text { identified and recruited, but the prototype project plan has not } \\
\text { been completed. }\end{array}$ & 0 \\
\hline $\begin{array}{l}\text { Testing plan } \\
\text { created but no } \\
\text { testing started }\end{array}$ & $\begin{array}{l}\text { The prototype project plan has been completed and reviewed. } \\
\text { Individuals or teams have been assigned tasks, but no testing } \\
\text { cycles have been initiated. }\end{array}$ & 2 \\
\hline $\begin{array}{l}\text { Testing cycle } \\
\text { initiated, but no } \\
\text { changes }\end{array}$ & $\begin{array}{l}\text { Initial cycles for learning and testing have begun (measurement, } \\
\text { data collection, study of processes, surveys, etc.). }\end{array}$ & 4 \\
\hline $\begin{array}{l}\text { Modest } \\
\text { improvement }\end{array}$ & $\begin{array}{l}\text { Successful tests of change have been completed. Anecdotal } \\
\text { evidence of improvement exists. Expected results and goals are } \\
\text { 25\% complete. }\end{array}$ & 6 \\
\hline $\begin{array}{l}\text { Significant } \\
\text { Progress }\end{array}$ & $\begin{array}{l}\text { Prototype/Pilot (training, communication, etc.) has begun for the } \\
\text { system impacted by the project. Project goals are more than 50\% } \\
\text { complete. }\end{array}$ & 8 \\
\hline $\begin{array}{l}\text { Outstanding } \\
\text { Success }\end{array}$ & $\begin{array}{l}\text { Implementation cycles have been completed and all project goals } \\
\text { and expected results have been accomplished. Organizational } \\
\text { changes have been made to accommodate improvements and to } \\
\text { make the project changes permanent. }\end{array}$ & 10 \\
\hline
\end{tabular}

Table 2 Self-Assessment key of team leaders 
In our experiments, we used three different types of variables: creativity indicator, structure indicators and content indicators. Each month, the team leaders have to self-evaluate their team's performance on a score from 0 to 10, which is taken as an indicator of the creativity of the team. The self-assessment key is illustrated in table 2. Structure indicators such as network density, degree centrality and betweenness centrality were directly computed using the Condor software package. Content indicators consist of two parts, one of which measures the sentiment of the emails including positivity, negativity and their mean values, while the second part estimates the focus of the prototype. As mentioned above, the email network for each prototype is built by filtering for descriptive and distinctive search words. If an email contains terms not just for a particular prototype, but for different ones, it will be counted for each subproject. Thus "openness" and "focus" of the subproject are introduced to asses the focus of the communication, "openness" tracks the proportion of team communication about one prototype also including discussion about other subprojects, focus equals 1 - openness. A detailed description of these indicators is listed in table 3.

\begin{tabular}{|c|c|c|}
\hline & Variable & Description \\
\hline $\begin{array}{l}\text { Creativity } \\
\text { Indicator }\end{array}$ & Score & $\begin{array}{l}\text { Team leader self-assessment of monthly performance of prototype } \\
\text { (dependent variable). This is the indicator for the creativity of the team }\end{array}$ \\
\hline \multirow{8}{*}{$\begin{array}{l}\text { Structure } \\
\text { Indicator }\end{array}$} & Age & How many months this project has been worked on? \\
\hline & Density & \multirow{3}{*}{$\begin{array}{l}\text { Social network metrics calculated in Condor } \\
\text { (1): a tie in the network is constructed if two actors have at least exchanged } \\
\text { one e-mail in the current month. } \\
\text { (2): a tie in the network is constructed if two actors have at least exchanged } \\
\text { two e-mails in the current month. }\end{array}$} \\
\hline & Degree & \\
\hline & Betweenness & \\
\hline & Node\# & How many people are talking about this prototype in the current month? \\
\hline & Day\# & How many days in the month people communicate with their team members? \\
\hline & Email\# & How many emails team members exchange in the current month? \\
\hline & Email\#(rec) & How many recipients these emails reach in the current month. \\
\hline \multirow{8}{*}{$\begin{array}{l}\text { Content } \\
\text { Indicator }\end{array}$} & Positivity $(+)$ & Cumulated positive sentiment value for the current month. \\
\hline & Negativity $(-)$ & Cumulated negative sentiment value for the current month \\
\hline & avg+/day & Average positive sentiment value per day \\
\hline & avg-/day & Average negative sentiment value per day \\
\hline & avg+/email & Average positive sentiment value per email \\
\hline & avg-/email & Average negative sentiment value per email \\
\hline & Openness of A & $\begin{array}{l}\text { The proportion of team communication of prototype A also including } \\
\text { discussion about other prototypes }\end{array}$ \\
\hline & Focus of A & 1- openness of $\mathrm{A}$ \\
\hline
\end{tabular}

Table 3 Networking and dependent variable description

\section{Results}

We find that social networking structure, sentiment, and word usage indeed predict creative performance of a team. To test the correlation between the variables, the following experiments were carried out.

Experiment 1: Each month is considered an individual data point. Structure indicators and content indicators of each e-mail network were computed, and compared with the team creativity of the same month $(\mathrm{N}=84)$. 
Experiment 2: The last score over the lifetime of a prototype was compared with the indicators of the aggregated network over the entire duration $(\mathrm{N}=12)$.

Experiment 3: All ratings for projects with the same score were aggregated, i.e. taking the average numbers of actors (Node\#) for all projects scoring one of $0,2,4,5,6$; the average number of e-mails sent (Email\#) for all projects scoring one of $0,2,4,5,6$, etc. There were only projects scored at $0,2,4,5,6$, which means that we got 5 data points for each variable in table $3(\mathrm{~N}=5)$.

The results of experiment 1 are illustrated in table 4 . When looking at network structure, we find that group density is negatively correlated with the performance score, while the number of actors involved (Node\#) and number of e-mails sent to different recipients (Email\#(rec)) are positively correlated with score. This is not surprising with regards to the number of actors and e-mails, as it means that the more people are involved into creating a prototype, and the more messages they exchange, the higher is team performance. The negative correlation for density means that the sparser the connection among as many different people as possible is, the higher the project is scored. To put it in other words, people should only communicate with alters who are needed to accomplish their task, while including too many links to unrelated people will lower team performance. These evidences support hypotheses H1, H2, and H3.

Secondly, the average number of positive and negative messages sent per day is positively correlated with the score, which means that the more people are outspoken when talking about a project, the higher it is scored, supporting hypothesis H4.

\begin{tabular}{|c|c|c|}
\hline \multirow[t]{3}{*}{ Density(1) } & Pearson Correlation & $-.241 *$ \\
\hline & Sig. (2-tailed) & .028 \\
\hline & $\mathrm{N}$ & 84 \\
\hline \multirow[t]{3}{*}{ Node\#(2) } & Pearson Correlation & $.257^{*}$ \\
\hline & Sig. (2-tailed) & .018 \\
\hline & $\mathrm{N}$ & 84 \\
\hline \multirow[t]{3}{*}{ Email\# } & Pearson Correlation & $.231 *$ \\
\hline & Sig. (2-tailed) & .035 \\
\hline & $\mathrm{N}$ & 84 \\
\hline \multirow[t]{3}{*}{ Positivity $(+)$} & Pearson Correlation & $.237 *$ \\
\hline & Sig. (2-tailed) & .030 \\
\hline & $\mathrm{N}$ & 84 \\
\hline \multirow[t]{3}{*}{ avg+/day } & Pearson Correlation & $.310 * *$ \\
\hline & Sig. (2-tailed) & .004 \\
\hline & $\mathrm{N}$ & 84 \\
\hline \multirow[t]{3}{*}{ avg-/day } & Pearson Correlation & $.228^{*}$ \\
\hline & Sig. (2-tailed) & .037 \\
\hline & $\mathrm{N}$ & 84 \\
\hline \multirow[t]{3}{*}{ avg+/email } & Pearson Correlation & $.242 *$ \\
\hline & Sig. (2-tailed) & .027 \\
\hline & $\mathrm{N}$ & 84 \\
\hline
\end{tabular}

Table 4. Significant correlations between networking variables and team score in experiment 1.

The same phenomenon is also found in experiment 3 (see table 5). With fewer data points, the correlation between performance score and networking variables becomes much stronger. Furthermore, we regressed project score against all structural and contents based variables, aggregating all projects by score (Figure 3 ), i.e. taking the average numbers of actors on score 0 , number of e-mails sent on score 0 , density on score 0 , etc $(\mathrm{N}=5)$. We found that just the average number of positive messages sent per day leads to an adjusted $\mathrm{R}^{2}$ of 0.963 (significant on the 0.001 level), while all other variables fell out as non-significant. This means that the number of positive messages sent per day alone explains $96 \%$ of the project success. 
This allows of course no conclusion on causality: does a project become more successful because project members send more positive e-mails, or do they send more positive e-mails because of a project's success. We speculate that causality might go both ways: once a project is on a positive trajectory, team members will be talking more positively about it.

\begin{tabular}{|l|l|r|}
\hline \multirow{5}{*}{ Density(1) } & Pearson Correlation & $-.978^{* *}$ \\
\cline { 2 - 3 } & Sig. (2-tailed) & .004 \\
\cline { 2 - 3 } & $\mathrm{N}$ & 5 \\
\hline \multirow{5}{*}{ Eode\#(2) } & Pearson Correlation & $.919^{*}$ \\
\cline { 2 - 3 } & Sig. (2-tailed) & .027 \\
\cline { 2 - 3 } & $\mathrm{N}$ & 5 \\
\hline Positivity (+) & Pearson Correlation & $.962^{* *}$ \\
\cline { 2 - 3 } & Sig. (2-tailed) & .009 \\
\cline { 2 - 3 } & $\mathrm{N}$ & 5 \\
\hline avg+/day & Pearson Correlation & $.963^{* *}$ \\
\cline { 2 - 3 } & Sig. (2-tailed) & .008 \\
\cline { 2 - 3 } & $\mathrm{N}$ & 5 \\
\hline \multirow{3}{*}{ avg-/day } & Pearson Correlation & $.986^{* *}$ \\
\cline { 2 - 3 } & Sig. (2-tailed) & .002 \\
\cline { 2 - 3 } & $\mathrm{N}$ & 5 \\
\hline & Pearson Correlation & .003 \\
\cline { 2 - 3 } & Sig. (2-tailed) & 5 \\
\cline { 2 - 3 } & $\mathrm{N}$ & 50 \\
\hline
\end{tabular}

Table 5. Significant correlations between networking variables and team score in experiment 3.
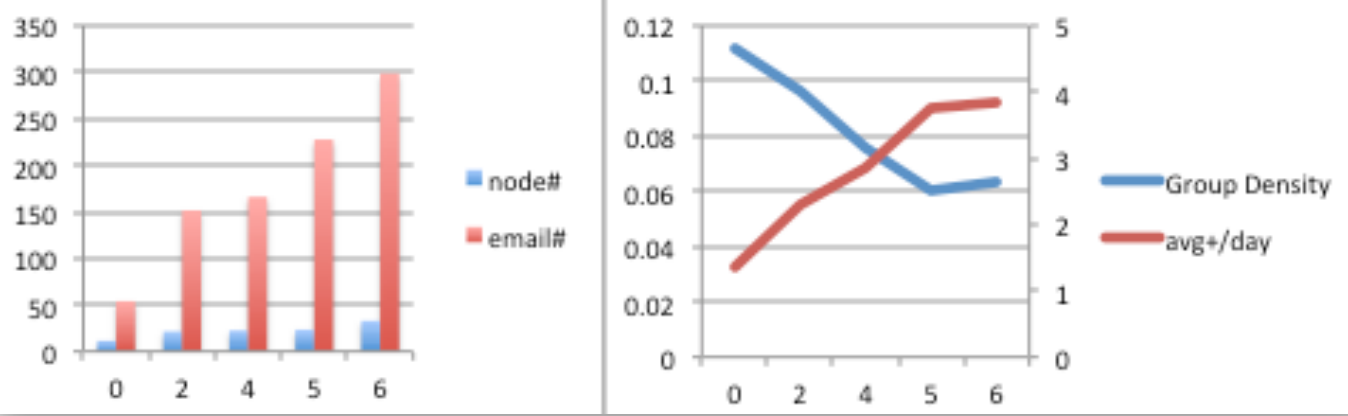

Figure 3. Projects aggregated by score levels (from 0 to 6), plotted against number of actors, numbers of e-mails sent, group density, and average number of positive messages sent per day (avg+/day)

We also find significant correlations for openness and focus with age of a project (table 6), with team members tending to become more focused and less open in the content they exchange as the project becomes more mature. Focus of the prototype positively correlated with the age of a project, supporting evidence to hypothesis 6 . As a project gets older, group density goes down and more actors are involved, sending more e-mails, which may imply that the project attracts more attention as time goes by. In general, networks tend to become less dense as they grow in size (Burt, 2000). 


\begin{tabular}{|l|l|r|}
\hline \multicolumn{2}{|c|}{} & \multicolumn{1}{|c|}{ Age } \\
\hline \multirow{3}{*}{ Density } & Pearson Correlation & $-.246^{*}$ \\
\cline { 2 - 3 } & Sig. (2-tailed) & .024 \\
\cline { 2 - 3 } & $\mathrm{N}$ & 84 \\
\hline \multirow{3}{*}{ Openness } & Pearson Correlation & $-.305^{* *}$ \\
\cline { 2 - 3 } & Sig. (2-tailed) & .005 \\
\cline { 2 - 3 } & $\mathrm{N}$ & 84 \\
\hline Focus & Pearson Correlation & $.305^{* *}$ \\
\cline { 2 - 3 } & Sig. (2-tailed) & .005 \\
\cline { 2 - 3 } & $\mathrm{N}$ & 84 \\
\hline
\end{tabular}

Table 6. Correlations between age and openness and focus in experiment 1.

\section{Discussion}

The results of this study indicate that as a creative project team progresses towards more mature phases, it attracts more attention from many different actors. This is supported by the findings that group density decreased over time, while more actors were getting involved, and more emails were exchanged. Through the application of content analysis we found that team members tend to become more focused in the message content they exchange via email as the project becomes more mature. A reason for this could be that people are more interested in joining an innovative team, which increases the chances for the team to be successful and reach higher creative performance. Furthermore, as a team becomes more mature, there might be an emotional attachment to the project that pushes members to work more creatively in order to reach the team's goal.

The combined results that as teams proceed into a more mature phase, actors exchange more emails, and density decreases seem to confirm the phenomenon that social cognitive science refers to as 'observational learning' (Bandura, 1986). Observing a team of creative people working together towards a common goal might be an enabling factor for improving the success of the team, as more creative people want to get involved and share the goal. This might represent an interesting managerial implication for organizational leaders who should sponsor the formation of COINs and facilitate the creation of external links with creative people outside of the organizational boundaries.

This study relies on email mining to investigate the content exchanged within and across project teams. Different project teams are filtered based on a few distinctive keywords per project. In other work we have compared team selection by content filtering with filtering by team membership and with aggregating individual network metrics of team members in the combined network. We found that all three approaches lead to significant results.

Although this might seem a limitation of our research method, since actors could exchange ideas via different other media, we believe that email represents a good approximation of the social network in this context. Our study involved project teams whose members were medical researchers, physicians, patients and caretakers. Because of their different geographic locations these creative teams - or COINs - heavily relied on emails to exchange ideas, documents and coordinate their activities. Conducting a structural analysis of the team network, together with a semantic analysis to investigate actors' opinion and word usage, provided a deeper level of understanding of the team dynamics.

An important contribution of this study is the identification of an alternative method to measure creativity within teams. Traditional methods have been based mainly on word association tests, 
psychological tests or survey/observation of human behavior. These studies were conducted in general within a laboratory setting (Amabile et al., 1996; Goncalo and Staw, 2006; Cummings and Kiesler, 2008). Our research provides empirical evidence that an integrated methodology combining social network analysis with content analysis might be an alternative or complementary technique to understand what leads to creative behaviors.

\section{Acknowledgements}

We would like to thank the members of the $\mathrm{C} 3 \mathrm{~N}$ project team at Cincinnati's Children's Hospital, Peter Margolis, Michael Seid, George Dellal, Molly Pace-Scrivener, Amy Martin, and Sophia Thurmond for their support, and for providing the basic data for this study.

\section{References}

Ahuja G. (2000) Collaboration networks, structural holes and innovation: a longitudinal study. Administrative Science Quarterly, 45(3), pp. 435-455.

Amabile, T.M. (1983) The social psychology of creativity: A componential conceptualization, Journal of Personality and Social Psychology, Vol. 45, No.2, pp. 357-376.

Amabile, T.M. (1996) Creativity in Context: Update to the Social Psychology of Creativity, Westview Press, Boulder, CO.

Amabile T.M., Conti R., Coon H., Lazenby J., Herron M. (1996) Assessing the Work Environment for Creativity, The Academy of Management Journal, Vol. 39, No. 5, pp. 1154-1184.

Bandura, A. (1986). Social foundations of thought and action: A social cognitive theory. Englewood Cliffs, NJ: Prentice-Hall.

Bo, P. Lee, L. and Vaithyanathan, S. (2002) Thumbs up?: sentiment classification using machine learning techniques. Proceedings of the ACL-02 conference on Empirical methods in natural language processing-Volume 10. Association for Computational Linguistics.

Bollen, J., Mao, H., \& Zeng, X. (2011). Twitter mood predicts the stock market. Journal of Computational Science, 2(1), 1-8.

Bulkley, N. and Van Alstyne M.W. (2006), An Empirical Analysis of Strategies and Efficiencies in Social Networks, Boston University School of Management Research Paper Series No. 2010-29, downloaded on April $12^{\text {th }}$ 2013, at http://ssrn.com/abstract=887406.

Burt, R.S. (2000) The Network Structure of Social Capital, in Sutton, R.I., Staw, B.M, Research in Organizational Behaviour, Jai Press, Greenwich, CT, vol.22.

Coleman, J.S. (1988) Social capital in the creation of human capital, American Journal of Sociology, 94, pp. 95-120.

Csikszentmihalyi, M. Creativity: Flow and the Psychology of Discovery and Invention. New York: Harper Perennial. 1997

Cummings, J. N., and Cross, R. (2003) Structural properties of work groups and their consequences for performance, Social Networks, 25(3), pp 197-210. 
Das, S. Chen, M. (2001). Yahoo! for Amazon: Extracting market sentiment from stock message boards. In Proc. of the 8th Asia Pacific Finance Association Annual Conference (APFA 2001).

Eysenck, H. J. (1993) 'Creativity and personality: Suggestions for a theory', Psychological Inquiry, 4, p.147-178.

Falchikov, N. (1986) 'Product Comparisons and Process Benefits of Collaborative Peer Group and Self Assessments', Assessment and Evaluation in Higher Education, Vol. 11, pp. 146-166.

Fuehres, H. Kaminski, J. Gloor, P. Zhang, X. Finding a Cure for Crohn's Disease - Analyzing Medical Conditions in Online Communities Proc. Sunbelt 2011, St. Pete's Beach FL, Feb. 10-13, 2011.

Gibson C.B and Gibbs J.L. (2006) Unpacking the concept of virtuality: The effects of geographic dispersion, electronic dependence, dynamic structure, and national diversity on team innovation, Administrative Science Quarterly, 51 (3), pp. 451-495.

Gloor, P. and Cooper, S. (2007) Coolhunting - Chasing Down The Next Big Thing, AMACOM, NY.

Gloor, P. (2006) Swarm Creativity, Competitive Advantage Through Collaborative Innovation Networks. Oxford University Press

Gloor, P. Oster, D. Fischbach, K. (2013) JazzFlow - Analyzing "Group Flow” among Jazz Musicians Through "Honest Signals". KI-Artifical Intelligence. Vol. 27, No. 1, pp 3743

Gloor, P, Oster, D, Raz, O, Pentland, A. and Schoder, D. (2008) The Virtual Mirror - Reflecting on Your Social and Psychological Self to Increase Organizational Creativity, Journal on International Studies of Management \& Organization, Vol. 40 No.2, pp 1-38.

Gloor, P., Fischbach, K., Fuehres, H., Lassenius, C., Niinimäki, T., Olguin Olguin, D., Pentland, A., Piri A. and Putzke, J. (2010) 'Towards "Honest Signals" of Creativity - Identifying Personality Characteristics Through Microscopic Social Network Analysis', Proc. of the COINs 2010, Collaborative Innovations Networks Conference, Savannah GA.

Gloor, P.A., Grippa, F., Borgert, A., Colletti, R., Dellal, G., Margolis, P. and Seid, M. (2010) Towards Growing a COIN in a Medical Research Community, paper presented at the Collaborative Innovations Networks Conference, Savannah GA, 7-9 October, 2010.

Gloor, P. Zhao, Y. (2006) Analyzing Actors and Their Discussion Topics by Semantic Social Network Analysis, Proceedings of 10th IEEE International Conference on Information Visualisation IV06, London, 5-7 July.

Gloor, P. Grippa, F. Putzke, J. Lassenius, C. Fuehres, H. Fischbach, K. Schoder, D. (2012) Measuring Social Capital in Creative Teams Through Sociometric Sensors. to appear in International Journal of Organizational Design and Engineering.

Goncalo J.A. and Staw B.M. (2006) 'Individualism-collectivism and group creativity', Organizational Behavior and Human Decision Processes, Vol. 100, pp. 96-109.

Goodwin, J. and Emirbayer, M. (1999) Network Analysis, Culture, and the problem of Agency, American Journal of Sociology, 99(6), pp. 1411-1454.

Granovetter, M., (1973) The strength of weak ties, American Journal of Sociology, Vol. 78, No. 6, pp. 1360-1380. 
Grant, A. M. and Berry, J. W. (2011) 'The Necessity of Others Is the Mother of Invention: Intrinsic and Prosocial Motivations, Perspective Taking, and Creativity', Academy of Management Journal, Vol. 54, No.1, pp. 73-96.

Hackman, J. R. and Katz, N. (2010) 'Group behavior and performance', In S. T. Fiske, D. T. Gilbert, and G. Lindzey (Eds.): Handbook of social psychology (5th ed.), pp. 1208-1251, Wiley, New York, NY.

Hansen, M.T (1999). The Search-Transfer Problem: The Role of Weak Ties in Sharing Knowledge across Organization Subunits, Administrative Science Quarterly, Vol. 44 N. 1, pp. 82-111.

Hatzivassiloglou, V. McKeown, K. (1997). Predicting the semantic orientation of adjectives. ACL '98 Proceedings of the 35th Annual Meeting of the Association for Computational Linguistics and Eighth Conference of the European Chapter of the Association for Computational Linguistics, pp 174-181.

Helson, R. (1996), In search of the creative personality, Creativity Research Journal, Vol. 9, pp. 295-306.

Kidane, Y. Gloor, P. (2007) Correlating temporal communication patterns of the Eclipse open source community with performance and creativity, Computational \& Mathematical Organization Theory. Volume 13, Issue 1 (March 2007), ISSN:1381-298X, 17 - 27.

Krauss, J., Nann, S., Simon, D., Fischbach K., Gloor, P. (2008) Predicting movie success and academy awards through sentiment and social network analysis, Proc. European Conference on Information Systems (ECIS), Galway, Ireland, June 9-11, 2008.

Moran P. (2005) Structural vs. relational embeddedness: social capital and managerial performance. Strategic Management Journal, 26(12), pp. 1129-1151.

Olguin-Olguin, D., Gloor, P. A., and Pentland, A. (2009) Wearable Sensors for Pervasive Healthcare Management. In: 3rd International Conference on Pervasive Computing Technologies for Healthcare, pp. 1-4. April 1-3, 2009. London, UK.

Perry-Smith Jill E. (2006) Social yet creative: the role of social relationships in facilitating individual Creativity, Academy of Management Journal, Vol. 49, No. 1, pp. 85-101.

Pirola-Merlo, A. \& Mann, L. (2004). The relationship between individual creativity and team creativity: aggregating across people and time. Journal of Organizational Behavior, 25, pp. 235-257.

Putnam, R. (2000). Bowling alone: the collapse and revival of American community. New York: Simon and Schuster.

Rost K. (2011) The strength of strong ties in the creation of innovation. Research Policy 40(4), pp. 588-604.

Sawyer, C. (2007) Group Genius: The Creative Power of Collaboration, Basic Books, New York, NY.

Simonton D.K. (1984). Genius, Creativity, and leadership: Historiometric inquiries. Cambridge, MA: Harvard University Press.

Shalley C.E. and Perry-Smith J.E. (2001) Effects of Social-Psychological Factors on Creative Performance: The Role of Informational and Controlling Expected Evaluation and Modeling Experience, Organizational Behavior and Human Decision Processes, Vol. 84, No. 1, pp. 1-22. 
Shepers P. and van den Berg P.T. (2007) Social Factors of Work-Environment Creativity, Journal of Business and Psychology, Vol. 21, No. 3, pp. 407-428.

Singh, B. (1986) Role of personality versus biographical factors in creativity, Psychological studies, Vol. 31(2), pp. 90-92.

Steiner G.A. (1969) The creative organization. Chicago: University of Chicago Press.

Sternberg, R. J., and Lubart, T.I. (1999) 'The Concept of Creativity: Prospects \& Paradigms', In R.J. Sternberg (Ed.): Handbook of creativity, pp.313-335, Cambridge University Press, New York.

Stinchcombe, A.L. (1990) Information and Organizations, Berkley, CA: University of California Press.

Woodman R.W., Sawyer J.E. and Griffin R.W. (1993) Toward a Theory of Organizational Creativity, The Academy of Management Review, Vol. 18, No. 2, pp. 293-321

Uzzi, B., and Spiro, J. (2005) 'Collaboration and Creativity: The Small World Problem', American Journal of Sociology, Vol. 111, No.2, pp. 447-504.

Wasserman, S. and Faust, K. (1994) Social Network Analysis: Methods and Applications, Cambridge University Press, Cambridge, UK.

Whitelaw, C. Garg, N. Argamon, S. (2005) Using Appraisal Groups for Sentiment Analysis, Proceedings of the 14th ACM international conference on Information and Knowledge Management, p. 631

Zhou, J. (2003) 'When the presence of creative coworkers is related to creativity: Role of supervisor close monitoring, developmental feedback, and creative personality', Journal of Applied Psychology, Vol. 88, pp. 413-422. 